\title{
Effects of fast-track anesthesia on miR-1 and neuropeptides in serum of patients undergoing cardiac surgery
}

\author{
HONGXIA ZHANG ${ }^{1}$, YONGJIAN CHAI ${ }^{2}$, QINGGANG LI ${ }^{3}$, QINGTAO HAN ${ }^{4}$ and ZHENQIAN LV ${ }^{5}$ \\ ${ }^{1}$ Department of Anesthesiology, Jining No. 1 People's Hospital, Jining, Shandong 272011; \\ ${ }^{2}$ Department of Anesthesiology, First People's Hospital of Jinan, Jinan, Shandong 250000; \\ ${ }^{3}$ Medical Department and ${ }^{4}$ Interventional Vascular Diseases, The People's Hospital of Zhangqiu Area, \\ Jinan, Shandong 250200; ${ }^{5}$ Cardiac Surgery, Qingdao Fuwai Cardiovascular Disease Hospital, \\ Qingdao, Shandong 266034, P.R. China
}

Received May 10, 2019; Accepted November 11, 2019

DOI: $10.3892 /$ etm.2020.8823

\begin{abstract}
Effects of fast-track anesthesia (FTA) on miR-1 and neuropeptides in serum of patients undergoing cardiac surgery were investigated. A total of 147 patients who underwent cardiac surgery at Jining No. 1 people's Hospital from August 2015 to July 2018 were selected. There were 72 patients who received the FTA technology during cardiac surgery in the intervention group, and 75 patients who received routine anesthesia during cardiac surgery in the control group. Venous blood was, respectively, collected before anesthesia (T0), 30 min after artery opening (T1), $60 \mathrm{~min}$ after artery opening (T2), and 180 min after artery opening (T3). Expression of serum miR-1 in patients at T0 to T3 were detected by real-time fluorescence quantitative PCR. Expression of neuropeptide indexes such as neuron-specific enolase (NSE), S100 $\beta$ protein $(S 100 \beta)$, and amyloid $\beta$-protein $(A \beta)$ in serum of patients in the two groups at T0 to T3 were detected by ELISA, and the correlation of expression of serum miR-1, serum NSE, S100 $\beta$ and $\mathrm{A} \beta$ was analyzed. There was no significant difference in the expression of serum miR-1 between the two groups at T0 $(\mathrm{P}>0.05)$. There was no significant difference in the expression of NSE, S100 $\beta$ and A $\beta$ between the two groups at T0 $(P>0.05)$. Expression of serum NSE, S100 $\beta$ and $A \beta$ in both groups increased gradually, and expression of serum NSE, $\mathrm{S} 100 \beta$ and $\mathrm{A} \beta$ in the intervention group were significantly lower than those in the control group at T1-T3 $(\mathrm{P}<0.05)$. There was a positive correlation between expression of serum miR-1, serum NSE, S100 $\beta$ and $A \beta(r=0.773, P<0.05 ; r=0.683$, $\mathrm{P}<0.05 ; \mathrm{r}=0.769, \mathrm{P}<0.05)$. Application of the FTA technology in cardiac surgery can effectively reduce the level of serum
\end{abstract}

Correspondence to: Dr Zhenqian Lv, Cardiac Surgery, Qingdao Fuwai Cardiovascular Disease Hospital, 201 Nanjing Road, Qingdao, Shandong 266034, P.R. China

E-mail: zdvp55@163.com

Key words: fast-track anesthesia, cardiac surgery, neuronspecific enolase, miR-1, S100 $\beta$ protein, amyloid $\beta$-protein
miR-1 in patients undergoing surgical treatment and improve their neurological function.

\section{Introduction}

As a common clinical cardiovascular disease, heart disease has a high morbidity and mortality, and studies have shown that the mortality of patients with heart disease has increased gradually in recent years $(1,2)$. Cardiac surgery is one of the main methods for the treatment of heart disease, and with the continuous development of medical technology, cardiac surgery technology is increasingly widely used in clinical practice (3). However, in cardiac surgery, it is necessary to use ligature in the blood vessels and then open them again. In this process, myocardial cells may undergo ischemia reperfusion and oxidative stress, which may cause certain damage to the myocardial cells $(4,5)$.

In all cardiac surgery procedures, anesthesia is required, but due to different anesthesia methods and choices of anesthetic drugs, the influence on myocardial cells is also different, so how to choose anesthesia methods to improve the protection of myocardial cells is one of the key issues in current clinical studies (6). Fast-track anesthesia (FTA) is a new anesthesia method gradually applied in recent years. It can improve the anesthesia effect by selecting anesthesia drugs immediately after surgery or within $6 \mathrm{~h}$ after surgery, and at the same time, it can better control the depth of anesthesia, in order to maintain the perioperative hemodynamic temperature and reduce the postoperative mechanical ventilation, so that patients can extubate as soon as possible (7). In recent years, FTA has been widely used in cardiac surgery, and studies have also confirmed that FTA plays an important and positive role in the stability of patients' intraoperative vital signs and the improvement of prognosis (8). miR-1 is an endogenous non-coding microRNA and there are studies (9) indicating that miR-1 has a protective effect on myocardial cell apoptosis during ischemia reperfusion injury, and may be involved in the process of oxidative stress and myocardial injury, but its mechanism remains to be further explored. Troponin has a good correlation, which can be used to evaluate the degree of myocardial ischemia reperfusion 
Table I. General materials $[\mathrm{n}(\%)]$.

\begin{tabular}{|c|c|c|c|c|}
\hline Items & $\begin{array}{l}\text { Intervention group } \\
\qquad(\mathrm{n}=72)\end{array}$ & $\begin{array}{l}\text { Control group } \\
\quad(\mathrm{n}=75)\end{array}$ & $\chi^{2}$ value & P-value \\
\hline Sex & & & 0.003 & 0.956 \\
\hline Male & $40(55.56)$ & $42(56.00)$ & & \\
\hline Female & $32(44.44)$ & $33(44.00)$ & & \\
\hline Age (years) & & & 0.019 & 0.890 \\
\hline$\leq 41$ & $28(38.89)$ & $30(40.00)$ & & \\
\hline$>41$ & $44(61.11)$ & $45(60.00)$ & & \\
\hline BMI $\left(\mathrm{kg} / \mathrm{m}^{2}\right)$ & & & 0.010 & 0.919 \\
\hline$\leq 22$ & $33(45.83)$ & $35(46.67)$ & & \\
\hline$>22$ & $39(54.17)$ & $40(53.33)$ & & \\
\hline Family history & & & 0.125 & 0.724 \\
\hline Yes & $26(36.11)$ & $25(33.33)$ & & \\
\hline No & $46(63.89)$ & $50(66.67)$ & & \\
\hline Smoking & & & 0.001 & 0.988 \\
\hline Yes & $22(30.56)$ & $23(30.67)$ & & \\
\hline No & $50(69.44)$ & $52(69.33)$ & & \\
\hline Alcohol consuption & & & 0.091 & 0.763 \\
\hline Yes & $28(38.89)$ & $31(41.33)$ & & \\
\hline No & $44(61.11)$ & $44(58.67)$ & & \\
\hline Complication of drug history & & & 0.190 & 0.890 \\
\hline Diabetes & $28(38.89)$ & $30(40.00)$ & & \\
\hline Hypertension & $44(61.11)$ & $45(60.00)$ & & \\
\hline Type of surgery & & & 0.330 & 0.997 \\
\hline Repair of atrial septal defect & $22(30.55)$ & $21(28.00)$ & & \\
\hline Repair of ventricular septal defect & $17(23.61)$ & $19(25.33)$ & & \\
\hline $\begin{array}{l}\text { Extracorporal coronary artery } \\
\text { bypass grafting }\end{array}$ & $12(16.67)$ & $13(17.33)$ & & \\
\hline $\begin{array}{l}\text { Off-pump coronary artery } \\
\text { bypass grafting }\end{array}$ & $9(12.50)$ & $8(10.67)$ & & \\
\hline Aortic valve replacement & $5(6.94)$ & $6(8.00)$ & & \\
\hline Ligation of ductus arteriosus & $7(9.72)$ & $8(10.67)$ & & \\
\hline
\end{tabular}

injury. Neuropeptide NSE, S100 $\beta$ protein (S100 $\beta$ ) and amyloid $\beta$-protein $(A \beta)$ are considered as important indicators to reflect the neurological function, they can reflect the neurological function of the body (10).

At present, most of the studies on the application of FTA in cardiac surgery have discussed the indicators such as intraoperative vital signs and the influence on prognosis, but there is still no detailed study on how FTA regulates the functions of the body and its potential molecular targets. Therefore, we explored the influence of FTA and routine anesthesia on miR-1 and neuropeptide in serum of patients undergoing cardiac surgery, in order to provide more theoretical explanations for the mechanism of FTA in cardiac surgery.

\section{Patients and methods}

General materials. A total of 147 patients who were admitted in Jining No. 1 people's Hospital (Jining, China) for cardiac surgery from August 2015 to July 2018 were selected, including 82 males and 65 females. The patients were evaluated at the age of $41.33 \pm 3.25$ years. There were 72 patients who received FTA technology during cardiac surgery in the intervention group and 75 patients who received routine anesthesia during cardiac surgery in the control group. There was no significant difference in sex, age or BMI between the two groups $(\mathrm{P}>0.05)$, which thus were comparable (Table I). The hospital is a governmental hospital, and all the patients were referrals. The sample size was determined in accordance with the formula $\mathrm{n}=\mathrm{C} 2 \sigma 2 / \mathrm{p} 2$ (11). The inclusion and exclusion criteria were as follows: The inclusion criteria: Patients diagnosed with heart disease, and patients undergoing first cardiac surgery. The exclusion criteria: Patients with severe hepatorenal dysfunction, surgical contraindications, malignant tumor disease, or coagulation dysfunction were excluded, patients who did not cooperate with the experiment were excluded, and patients with cognitive or communication disorders were excluded. 
Table II. Primer sequences.

\begin{tabular}{lll}
\hline Gene & \multicolumn{1}{c}{ Upstream primers } & \multicolumn{1}{c}{ Downstream primers } \\
\hline miR-1 & 5'-GAGCAGGCTGGAGAA-3' & 5'-GGTGGAATGTAAAGAAGTC-3' \\
GAPDH & 5'-AACGACCCCTCATTGACCTC-3' & 5'-CCTTGACTGTGCCGTTGAACT-3' \\
\hline
\end{tabular}

The patients, and their families, agreed to the participation in the study and signed an informed consent form. This study was approved by the Ethics Committee of Jining No. 1 People's Hospital (no. JNPH201403A).

Experimental materials and reagents. Experimental materials were as follows: Scopolamine hydrobromide injection (Shanghai Hefeng Pharmaceutical Co., Ltd., SFDA approval no. H31021519); pethidine hydrochloride injection (Yichang Renfu Pharmaceutical Co., Ltd., SFDA approval no. H42022074); etomidate injection (Jiangsu Enhua Pharmaceutical Co., Ltd., SFDA approval no. H20020511); sufentanil citrate injection (Yichang Renfu Pharmaceutical Co., Ltd., SFDA approval no. H20054172); midazolam injection (Jiangsu Enhua Pharmaceutical Co., Ltd., SFDA approval no. H20031037); propofol injection (Xi'an Libang Pharmaceutical Co., Ltd., SFDA approval no. H20010368). Real-time quantitative PCR was from American Bio-Rad Company; TRIzol reagent was from American Applide Invitrogen Company; qPCR kit and miScript RT-PCR kit were from Dalian Takara Company; miR-1 and internal reference GAPDH primers were synthesized and designed by Shanghai Gemma Company. NSE ELISA kit was from Nanjing Senbega Biotechnology Co., Ltd., art. no. Sbj-r0571. S100 $\beta$ ELISA kit was from Wuhan Aimeijie Technology Co., Ltd., art. no. KA0037. The A $\beta$ ELISA kit was from Wuhan Merck Biotechnology Co., Ltd., art. no. 69-99391. Cisatracurium was from Zhejiang Xianyi Pharmaceutical Co., Ltd., SFDA approval no. H20090202. Remifentani was from Jiangsu Enhua Pharmaceutical Co., Ltd., SFDA approval no. H20143314.

Methods of anesthesia. The patients were routinely deprived of food and water for $6 \mathrm{~h}$ before surgery. After entering the operating room, the patients' vital signs, including heart rate, blood pressure and blood oxygen saturation were monitored by ECG, and then intravenous channels were established routinely. Patients in the control group were treated by routine anesthesia. Specifically, $0.3 \mathrm{mg}$ scopolamine and $1 \mathrm{mg} / \mathrm{kg}$ pethidine were injected intramuscularly half an hour before surgery. After entering the operating room, anesthesia induction was conducted by intravenous injection of $0.1 \mathrm{mg} / \mathrm{kg}$ cisatracuramine, $10 \mu \mathrm{g} / \mathrm{kg}$ fentanyl and $20 \mathrm{mg} / \mathrm{kg}$ propofol. After successful anesthesia induction, the trachea was intubated and connected to the anesthesia ventilator, anesthesia was maintained by continuous intravenous pumping of $8 \mu \mathrm{g} /(\mathrm{kg} \cdot \mathrm{min})$ propofol and $5 \mu \mathrm{g} /(\mathrm{kg} \cdot \mathrm{min})$ fentanyl, and the anesthetic was discontinued $10 \mathrm{~min}$ before the end of surgery.

Patients in the observation group were anesthetized with FTA technology. Specifically, preoperative injection of scopolamine and pethidine was performed as the control group; $0.1 \mathrm{mg} / \mathrm{kg}$ cisatracurium, $0.1-0.3 \mathrm{mg} / \mathrm{kg}$ etomidate, 10 to $20 \mathrm{mg} / \mathrm{kg}$ propofol, 0.1 to $0.2 \mathrm{mg} / \mathrm{kg}$ midazolam, and $1 \mu \mathrm{g} / \mathrm{kg}$ sufentanil were used for anesthesia induction. The end-tidal carbon dioxide partial pressure was maintained between 30 and $35 \mathrm{mmHg}$. Then, 2-3\% sevoflurane was given through tracheal intubation to maintain anesthesia, and $1 \mu \mathrm{g} /(\mathrm{kg} \cdot \mathrm{min})$ sufentanil was added before incision and opening the chest. During the operation, 0.2-0.5 $\mu \mathrm{g} /(\mathrm{kmin})$ remifentanil and 3-6 $\mu \mathrm{g} /(\mathrm{kg} \cdot \mathrm{min})$ propofol were given for maintenance, bispectral index was between 30 and 45, cisatracurium was given continuously, bispectral index (BIS) was used to test the depth of anesthesia during operation, narcotic drugs were adjusted for maintaining the BIS between 40 and 50 , and sevoflurane was discontinued $30 \mathrm{~min}$ before the end of surgery. After the operation, the patient breathed spontaneously and extubated. Venous blood samples of the patients were collected respectively before anesthesia (T0), $30 \mathrm{~min}$ after artery opening (T1), $60 \mathrm{~min}$ after artery opening (T2), and $180 \mathrm{~min}$ after artery opening (T3) for indicator detection. Expression of neuropeptide indexes such as neuron-specific enolase (NSE), S100 $\beta$ protein (S100 $\beta$ ), and amyloid $\beta$-protein $(\mathrm{A} \beta)$ in serum of patients in the two groups at $\mathrm{T} 3$ were detected in strict accordance with the operating instructions of ELISA kit. In order to reduce the artificial difference between groups and make the results more accurate, all the cardiac surgeries were performed by the same team.

Real-time fluorescence quantitative PCR detection of the $m i R-1$. First, venous blood collected at T0-T3 time-points was centrifuged at $1,500 \times \mathrm{g}$ at $4^{\circ} \mathrm{C}$ for $10 \mathrm{~min}$, and serum was collected for detection after centrifugation. Total RNA was extracted by adding TRIzol reagent into the serum reagent tube, and the purity and concentration of RNA were determined by ultraviolet spectrophotometer. The ratio of OD260/OD280 was 1.92, and the ratio of OD260/OD230 was 2.13. Total RNA $(1 \mu \mathrm{g})$ was taken and cDNA was synthesized according to the instructions of the RT-PCR kit. Synthesized cDNA $(2 \mu \mathrm{l})$ was taken for qPCR. Reaction conditions were as follows: pre-denaturation at $95^{\circ} \mathrm{C}$ for $5 \mathrm{~min}$, then at $95^{\circ} \mathrm{C}$ for $15 \mathrm{sec}$, at $60^{\circ} \mathrm{C}$ for $20 \mathrm{sec}$, at $72^{\circ} \mathrm{C}$ for $20 \mathrm{sec}$, for 40 cycles. The expression level of miR-1 was detected by using GAPDH as an internal reference, and the experiment was repeated 3 times. The primer sequences are shown in Table II.

Observation indexes. i) Expression changes of miR-1 at T0 to T3 were compared between the two groups. ii) Expression of NSE, S100 $\beta$ and $A \beta$ at T0 to T3 were compared between the two groups. iii) Correlation analysis of expression between serum miR-1, NSE, S100 $\beta$ and A $\beta$ 


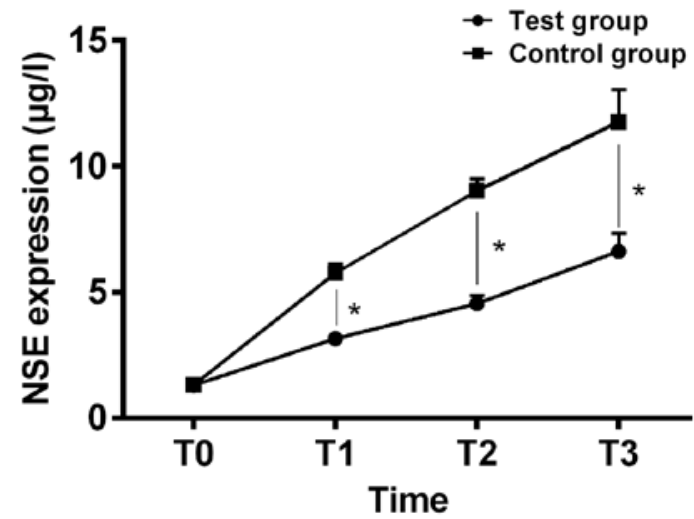

Figure 1. Comparison of expression of serum NSE of patients between the two groups at different time-points. ELISA analysis showed that there was no significant difference in expression of serum NSE between the two groups at T0 ( $\mathrm{P}>0.05)$, expression of serum NSE increased gradually during operation of patients in both groups, and expression of serum NSE of patients in the intervention group at $\mathrm{T} 1$ to $\mathrm{T} 3$ was significantly lower than those of patients in the control group, and the difference was statistically significant $(\mathrm{P}<0.05)$. ${ }^{*} \mathrm{P}<0.05$. NSE, neuron-specific enolase; ELISA, enzyme-linked immunosorbent assay.

in the intervention group. iv) Postoperative adverse events were recorded and compared between the two groups, including pharyngalgia, nausea and vomiting, and laryngospasms.

Statistical analysis. SPSS 18.0 (IBM Corp.) was adopted for statistical data analysis, GraphPad Prism 6 was used to draw the illustrations, the Chi-square test was used to compare the counting data, data were presented as mean \pm standard deviation, independent t-tests were used for comparison between the two groups, repeated measurement analysis of variance was used for comparison at different time-points, and Pearson's correlation method was used for correlation analysis. At $\mathrm{P}<0.05$, the difference was considered statistically significant.

\section{Results}

Expression of serum miR-1 at different time-points in the two groups. There was no significant difference in expression of serum miR-1 between the two groups at T0 ( $\mathrm{P}>0.05)$; expression of serum miR-1 in both groups increased gradually from $\mathrm{T} 0$ to T3, but the expression of serum miR-1 in the intervention group at T1 to T3 was significantly lower than that in the control group, and the difference was statistically significant $(\mathrm{P}<0.05)$ (Table III).

Expression of serum NSE, S100 $\beta$ and $A \beta$ at different time-points in the two groups. Expression of serum NSE at T0 to $\mathrm{T} 3$ were, respectively, $1.31 \pm 0.12,3.15 \pm 0.29,4.54 \pm 0.33$ and $6.62 \pm 0.73 \mu \mathrm{g} / \mathrm{l}$ of patients in the intervention group; expression of serum S100 $\beta$ was, respectively, $141.27 \pm 26.35,279.26 \pm 32.91$, $442.15 \pm 51.63$ and $532.75 \pm 84.36 \mathrm{ng} / \mathrm{l}$; expression of serum $A \beta$ was, respectively, $69.35 \pm 11.26,137.85 \pm 17.31,198.51 \pm 21.42$ and $264.46 \pm 29.46 \mathrm{ng} / \mathrm{l}$. Expression of serum NSE at T0 to T3 was, respectively, $1.32 \pm 0.13,5.76 \pm 0.35,9.02 \pm 0.47$ and $11.76 \pm 1.27 \mu \mathrm{g} / \mathrm{l}$ of patients in the control group; expression of serum S100 $\beta$ was, respectively, $143.01 \pm 25.32,386.41 \pm 42.36$, $581.33 \pm 67.25$ and $834.65 \pm 83.64 \mathrm{ng} / \mathrm{l}$; expression of serum $A \beta$

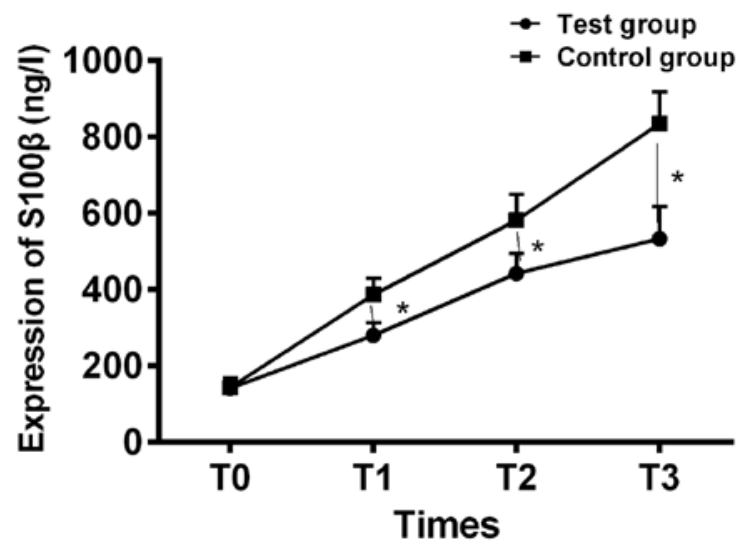

Figure 2. Comparison of expression of serum S100 $\beta$ of patients between the two groups at different time-points. ELISA analysis showed that there was no significant difference in expression of serum $\mathrm{S} 100 \beta$ between the two groups at T0 $(\mathrm{P}>0.05)$, expression of serum S100 $\beta$ increased gradually during the operation in both groups, and expression of serum $\mathrm{S} 100 \beta$ of patients in the intervention group at T1 to T3 was significantly lower than those of patients in the control group $(\mathrm{P}<0.05)$. ${ }^{*} \mathrm{P}<0.05$. ELISA, enzyme-linked immunosorbent assay.

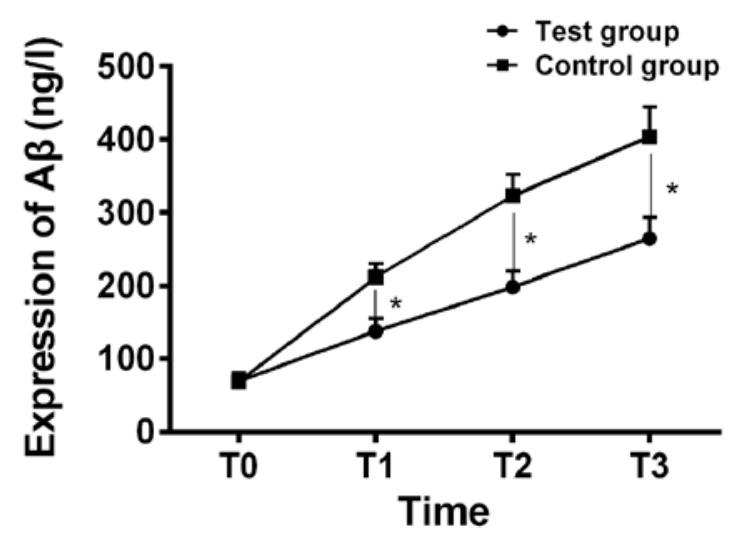

Figure 3. Comparison of expression of serum $A \beta$ of patients between the two groups at different time-points. ELISA analysis showed that there was no significant difference in expression of serum $A \beta$ between the two groups at T0 $(\mathrm{P}>0.05)$, and expression of serum A $\beta$ increased gradually of patients during the operation in both groups, and expression of serum $A \beta$ of patients in the intervention group at T1 to T3 was significantly lower than those of patients in the control group $(\mathrm{P}<0.05)$. ${ }^{*} \mathrm{P}<0.05$. ELISA, enzyme-linked immunosorbent assay.

was, respectively, $68.39 \pm 11.31,211.39 \pm 18.37,322.93 \pm 28.95$ and $403.64 \pm 40.72 \mathrm{ng} / \mathrm{l}$.

There was no significant difference in expression of NSE, S100 $\beta$ and $A \beta$ at T0 between the two groups ( $P>0.05$ ); expression of NSE, S100 $\beta$ and $A \beta$ in the serum of the two groups increased gradually, and expression of NSE, S100 $\beta$ and A $\beta$ in the serum at $\mathrm{T} 1$ to $\mathrm{T} 3$ of the intervention group were significantly lower than those of the control group, and the difference was statistically significant $(\mathrm{P}<0.05)$ (Figs. 1-3).

Correlation analysis of expression on serum miR-1 and serum $N S E, S 100 \beta$ and $A \beta$. There was a positive correlation between expression of serum miR-1 and serum NSE, S100 $\beta$ and A $\beta$ $(\mathrm{r}=0.773, \mathrm{P}<0.05) ; \mathrm{r}=0.683, \mathrm{P}<0.05 ; \mathrm{r}=0.769, \mathrm{P}<0.05)$ (Figs. 4-6).

Comparison of adverse reactions between the two groups. The number of patients with pharyngalgia, nausea and vomiting, 
Table III. Expression of serum miR-1 at different time-points in the two groups.

\begin{tabular}{lccr}
\hline Time-point & Intervention group $(\mathrm{n}=72)$ & Control group $(\mathrm{n}=75)$ & t value \\
\hline T0 & $0.31 \pm 0.04$ & $0.32 \pm 0.05$ & 1.336 \\
T1 & $2.05 \pm 0.11^{\mathrm{a}}$ & $2.97 \pm 0.12^{\mathrm{a}}$ & 48.40 \\
T2 & $3.22 \pm 0.13^{\mathrm{a}}$ & $4.71 \pm 0.15^{\mathrm{a}}$ & $<.184$ \\
T3 & $4.05 \pm 0.18^{\mathrm{a}}$ & $6.39 \pm 0.19^{\mathrm{a}}$ & $<.001$ \\
F-value & 12016 & 25987 & $<0.001$ \\
P-value & $<0.001$ & $<0.001$ & $<0.001$ \\
\hline
\end{tabular}

${ }^{\mathrm{a}} \mathrm{P}<0.05$ and $\mathrm{T} 1$ were compared.

Table IV. Comparison of adverse reactions between the two groups.

\begin{tabular}{lccr}
\hline Adverse reactions & Intervention group $(\mathrm{n}=72)$ & Control group $(\mathrm{n}=75)$ & $\chi^{2}$ value \\
\hline Pharyngalgia & $1(1.39)$ & $4(5.33)$ & 1.740 \\
Nausea and vomiting & $2(2.78)$ & $5(6.67)$ & 1.225 \\
Laryngospasm & 0 & $2(2.67)$ & 0.187 \\
Total & $3(4.17)$ & $11(14.56)$ & 0.268 \\
\hline
\end{tabular}

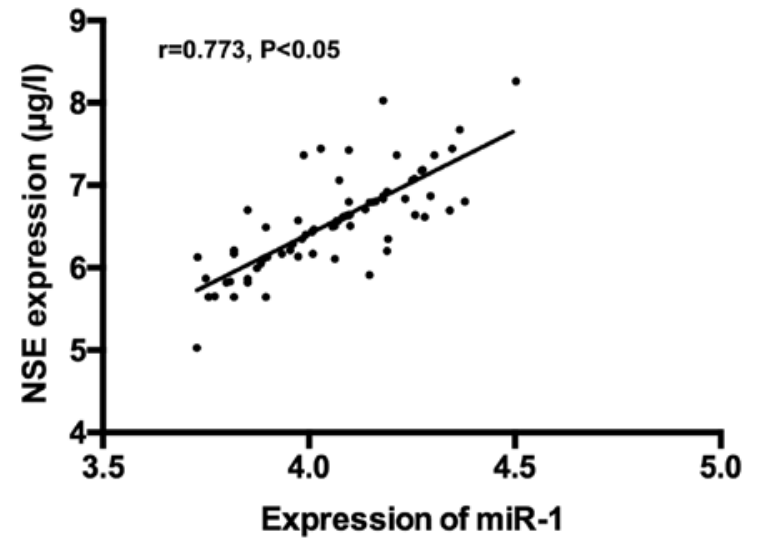

Figure 4. Correlation analysis of expression of serum miR-1 and serum NSE. Pearson's correlation analysis revealed a positive correlation of expression between serum miR-1 and serum NSE $(r=0.773, \mathrm{P}<0.05)$. NSE, neuron-specific enolase.

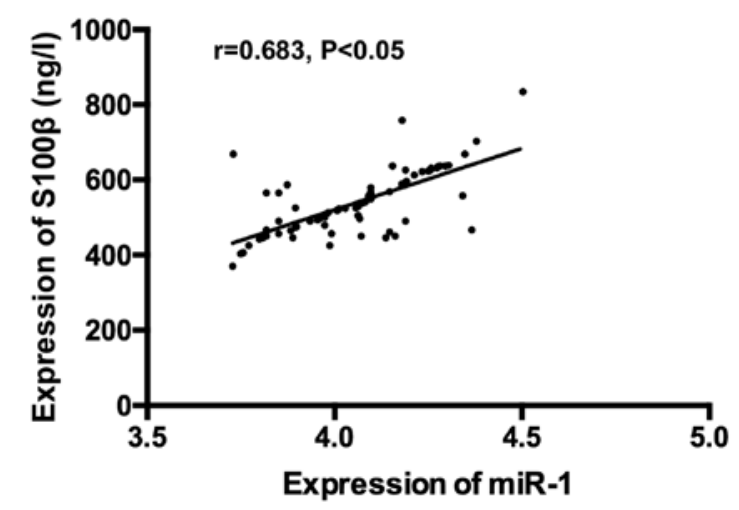

Figure 5. Correlation analysis of expression of serum miR-1 and serum S100 $\beta$. Pearson's correlation analysis revealed a positive correlation of expression between serum miR-1 and $\mathrm{S} 100 \beta(\mathrm{r}=0.683, \mathrm{P}<0.05)$.

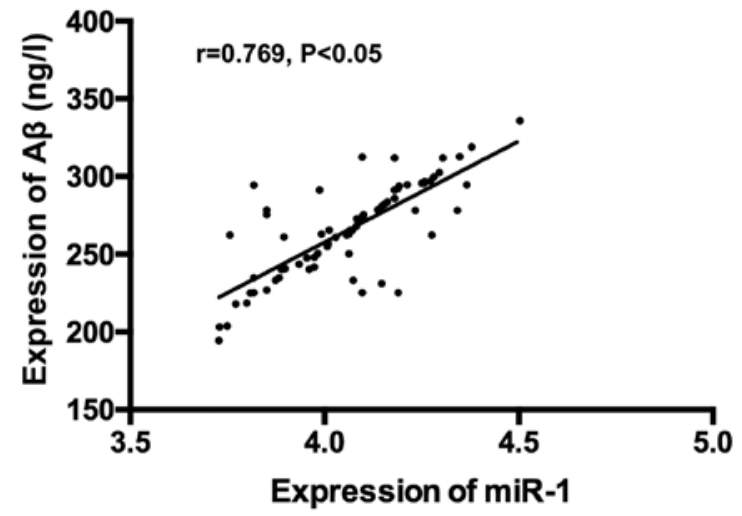

Figure 6. Correlation analysis of expression of serum miR-1 and serum A $\beta$. Pearson's correlation analysis revealed a positive correlation of expression between serum miR-1 and $\mathrm{A} \beta(\mathrm{r}=0.769, \mathrm{P}<0.05)$.

and laryngospasms in the intervention group were 1, 2 and 0 , respectively. The incidence of adverse reactions was $4.17 \%$. The number of patients with pharyngalgia, nausea and vomiting, and laryngospasms in the control group were 4, 5 and 2, respectively. The incidence of adverse reactions was $14.67 \%$. The incidence of adverse reactions in the intervention group was significantly lower than that in the control group, and the difference was statistically significant $(\mathrm{P}<0.05)$ (Table IV).

\section{Discussion}

FTA anesthesia technology developed in recent years, achieves a strong controllability of the depth of anesthesia and postoperative recovery through the use of controllable anesthesia drugs, so as to reduce the stress response of patients (12). As a new anesthesia technique, it has been widely used in cardiac 
surgery in recent years, and has been proved to have high safety (13). When implementing FTA technology, we used sufentanil to replace fentanyl, because sufentanil not only has stronger analgesic effects than fentanyl, but also can reduce vascular resistance and relax vascular smooth muscle $(14,15)$. Sevoflurane is selected for intraoperative anesthesia maintenance because of its high depth of anesthesia controllability, to avoid damage of excessive anesthesia on heart and nerve function (16).

miR-1 (also miRNA), has a close relationship with myocardial injury (17). Some studies on animal models with acute myocardial infarction caused by myocardial ischemia reperfusion injury found that the expression level of miR-1 in the serum of animal models with acute myocardial infarction was significantly increased, and the inhibition of expression of miR-1 could alleviate the damage caused by myocardial infarction (18). In this study, we found that although the expression level of miR-1 of patients in the two groups was increased during the operation, the expression level of serum miR-1 in the intervention group was significantly lower than that in the control group at $\mathrm{T} 1$ to $\mathrm{T} 3(\mathrm{P}<0.05)$, which suggested that FTA anesthesia technology had less impact on miR-1 in patients undergoing cardiac surgery. Previous studies (19) have suggested that miR-1 can aggravate the damage of oxidative free radicals and oxidative stress by inhibiting SOD and other factors. Previous studies (20) indicated that the application of FTA technology in heart surgery can effectively reduce patients' inflammatory and stress responses, which indirectly confirmed our conclusion. From this, we can also infer that FTA may alleviate the oxidative stress reaction of the body during the operation by controlling the upregulation of miR-1. Our results further demonstrated that miR-1 can reflect the level of oxidative stress and the degree of myocardial injury in the body after aorta opening, which may be used as a serological marker to evaluate oxidative stress and myocardial injury. However, at present, there has been no research on the impact of FTA technology on the intraoperative miR-1 level of patients undergoing cardiac surgery, so further verification is needed for our conclusions. In cardiac surgery, in addition to requiring anesthesia to protect cardiac myocytes and relieve oxidative stress, anesthesia is also required to reduce damage to the nervous system (21). So in order to explore the FTA anesthesia effects of nerve function in patients with cardiac surgery, we compared expression of serum NSE, S100 $\beta$ and $\mathrm{A} \beta$ in patients at different time-points during the operation. The results showed that expression of serum NSE, S100 $\beta$ and $\mathrm{A} \beta$ in both groups increased gradually, however, expression of serum NSE, S100 $\beta$ and $A \beta$ in the intervention group were significantly lower than those in the control group at T1 to T3 $(\mathrm{P}<0.05)$. This shows that cardiac surgery has a certain impact on the neurological function of patients, but the application of FTA technology can effectively alleviate and protect the neurological function of patients undergoing cardiac surgery. There are studies (22) that suggest that inflammation is one of the important factors that cause neuronal damage, and have found that the inflammatory response enhancement causes neurons and glial cells to release a large amount of NSE and S100 $\beta$, and create the accumulation of $A \beta$, thus further leading to nerve function injury in patients, and increase the risk of postoperative cognitive dysfunction. It has been reported (7) that FTA can effectively alleviate the patient's stress response and protect nerve function, which is similar to our results; but the anesthetic drugs were not the same as the drugs used in the present study, which made it impossible for us to determine whether the results were affected by the difference in drugs. Therefore, we speculate that FTA technology may protect patients' neurological functions by improving their intraoperative inflammatory responses. Some studies (23) have explored the application value of FTA in heart surgery, suggesting that FTA technology can effectively alleviate patients' inflammatory reaction, reduce the expression of NSE, S100 $\beta$ and A $\beta$ during the surgery, and improve patients' neurological function. This is also a good confirmation of our conclusions. We analyzed the correlation of expression between serum miR-1 and serum NSE, S100 $\beta$ and $A \beta$ in patients undergoing heart surgery. The results showed that there was a positive correlation of expression between serum miR- 1 and serum NSE, S100 $\beta$ and $A \beta$, which suggested that serum miR-1 was associated with serum NSE, S100 $\beta$ and A $\beta$ in patients undergoing cardiac surgery. The adverse reactions of the two groups of patients were compared, and the results showed that the complications of the intervention group were significantly lower than those of the control group, which suggested the safety of FTA for patients receiving cardiac surgery. However, at present, there is no relevant research on this aspect, so the specific mechanism of its connection remains to be further explored.

In conclusion, the application of the FTA technology in cardiac surgery can effectively reduce the level of serum miR-1 in patients undergoing surgical treatment and improve their neurological function.

\section{Acknowledgements}

Not applicable.

\section{Funding}

No funding was received.

\section{Availability of data and materials}

The datasets used and/or analyzed during the current study are available from the corresponding author on reasonable request.

\section{Authors' contributions}

$\mathrm{HZ}$ and YC analyzed and interpreted the patient data. QL and ZL performed the experiment and designed the study. HZ, YC, $\mathrm{QH}$ and $\mathrm{ZL}$ were responsible for the analysis and discussion of the data. HZ wrote the manuscript. All authors read and approved the final manuscript.

\section{Ethics approval and consent to participate}

The study was approved by the Ethics Committee of the Jining No. 1 People's Hospital (Jining, China). Patients who participated in this study, signed an informed consent and had complete clinical data. 


\section{Patient consent for publication}

Not applicable.

\section{Competing interests}

The authors declare that they have no competing interests.

\section{References}

1. Dhruva SS, Huang C, Spatz ES, Coppi AC, Warner F, Li SX, Lin H, Xu X, Furberg CD, Davis BR, et al: Heterogeneity in early responses in ALLHAT (Antihypertensive and Lipid-Lowering Treatment to Prevent Heart Attack Trial). Hypertension 70: 94-102, 2017.

2. Brown MJ: Matching the right drug to the right patient in essential hypertension. Heart 86: 113-120, 2001.

3. Beckmann A, Meyer R, Lewandowski J, Frie M, Markewitz A and Harringer W: German Heart Surgery Report 2017: The annual updated registry of the German society for thoracic and cardiovascular surgery. Thorac Cardiovasc Surg 66: 608-621, 2018.

4. Alderman MH, Piller LB, Ford CE, Probstfield JL, Oparil S, Cushman WC, Einhorn PT, Franklin SS, Papademetriou V, Ong ST, et al; Antihypertensive and Lipid-Lowering Treatment to Prevent Heart Attack Trial Collaborative Research Group: Clinical significance of incident hypokalemia and hyperkalemia in treated hypertensive patients in the antihypertensive and lipid-lowering treatment to prevent heart attack trial Hypertension 59: 926-933, 2012.

5. Lillvis JH and Lanfear DE: Progress toward genetic tailoring of heart failure therapy. Curr Opin Mol Ther 12: 294-304, 2010.

6. Khanykin B, Siddiqi R, Jensen PF, Bigler DR and Atroshchenko GV: Comparison of remifentanil and low-dose fentanyl for fast-track cardiac anesthesia: A prospective randomized study. Heart Surg Forum 16: E324-E328, 2013.

7. Tang CL, Li J, Zhang ZT, Zhao B, Wang SD, Zhang HM, Shi S, Zhang Y and Xia ZY: Neuroprotective effect of bispectral index-guided fast-track anesthesia using sevoflurane combined with dexmedetomidine for intracranial aneurysm embolization. Neural Regen Res 13: 280-288, 2018.

8. Lena P, Balarac N, Lena D, De La Chapelle A, Arnulf JJ, Mihoubi A, Tapia M and Bonnet F: Fast-track anesthesia with remifentanil and spinal analgesia for cardiac surgery: The effect on pain control and quality of recovery. J Cardiothorac Vasc Anesth 22: 536-542, 2008.

9. Kang B, Li W, Xi W, Yi Y, Ciren Y, Shen H, Zhang Y, Jiang H, Xiao J and Wang Z: Hydrogen sulfide protects cardiomyocytes against apoptosis in ischemia/reperfusion through miR-1-regulated histone deacetylase 4 pathway. Cell Physiol Biochem 41: 10-21, 2017.
10. Huang Q, Lin LY and Lin XZ: Comparison of remifentanil-based fast-track and fentanyl-based routine cardiac anesthesia for intraoperative device closure of atrial septal defect (ASD) in pediatric patients. Med Sci Monit 25: 1187-1193, 2019.

11. Sandelowski M: Sample size in qualitative research. Res Nurs Health 18: 179-183, 1995.

12. Çaparlar CÖ, Özhan MÖ, Süzer MA, Yazicioğlu D, Eşkin MB, Şenkal S, Caparlar MA, Imren EÖ, Atik B and Cekmen N: Fast-track anesthesia in patients undergoing outpatient laparoscopic cholecystectomy: Comparison of sevoflurane with total intravenous anesthesia. J Clin Anesth 37: 25-30, 2017.

13. Hijazi EM, Edwan H, Al-Zoubi N and Radaideh H: Incidence of nausea and vomiting after fast-track anaesthesia for heart surgery. Rev Bras Cir Cardiovasc 33: 371-375, 2018.

14. Villafranca A, Thomson IA, Grocott HP, Avidan MS, Kahn S and Jacobsohn E: The impact of bispectral index versus end-tidal anesthetic concentration-guided anesthesia on time to tracheal extubation in fast-track cardiac surgery. Anesth Analg 116: 541-548, 2013.

15. Turner ST, Schwartz GL and Boerwinkle E: Personalized medicine for high blood pressure. Hypertension 50: 1-5, 2007.

16. Cífková R: Antiplatelet and lipid-lowering drugs in hypertension. Eur Cardiol 9: 16-20, 2014

17. Chistiakov DA, Orekhov AN and Bobryshev YV: Cardiac-specific miRNA in cardiogenesis, heart function, and cardiac pathology (with focus on myocardial infarction). J Mol Cell Cardiol 94: 107-121, 2016.

18. Lai TL and Lavori PW: Innovative Clinical Trial Designs: Toward a 21st-century Health Care System. Stat Biosci 3: 145-168, 2011.

19. Gates BJ and Walker KM: Physiological changes in older adults and their effect on diabetes treatment. Diabetes Spectr 27: 20-28, 2014.

20. Pergola PE, White CL, Szychowski JM, Talbert R, Brutto OD, Castellanos M, Graves JW, Matamala G, Pretell EJ, Yee J, et al; SPS3 Investigators: Achieved blood pressures in the secondary prevention of small subcortical strokes (SPS3) study: Challenges and lessons learned. Am J Hypertens 27: 1052-1060, 2014.

21. Padmanabhan S, Paul L and Dominczak AF: The pharmacogenomics of anti-hypertensive therapy. Pharmaceuticals (Basel) 3: 1779-1791, 2010.

22. Mitchell JD, Maguire JJ and Davenport AP: Emerging pharmacology and physiology of neuromedin $U$ and the structurally related peptide neuromedin S. Br J Pharmacol 158: 87-103, 2009.

23. Hong KS: Blood pressure management for stroke prevention and in acute stroke. J Stroke 19: 152-165, 2017.

This work is licensed under a Creative Commons Attribution-NonCommercial-NoDerivatives 4.0 International (CC BY-NC-ND 4.0) License. 